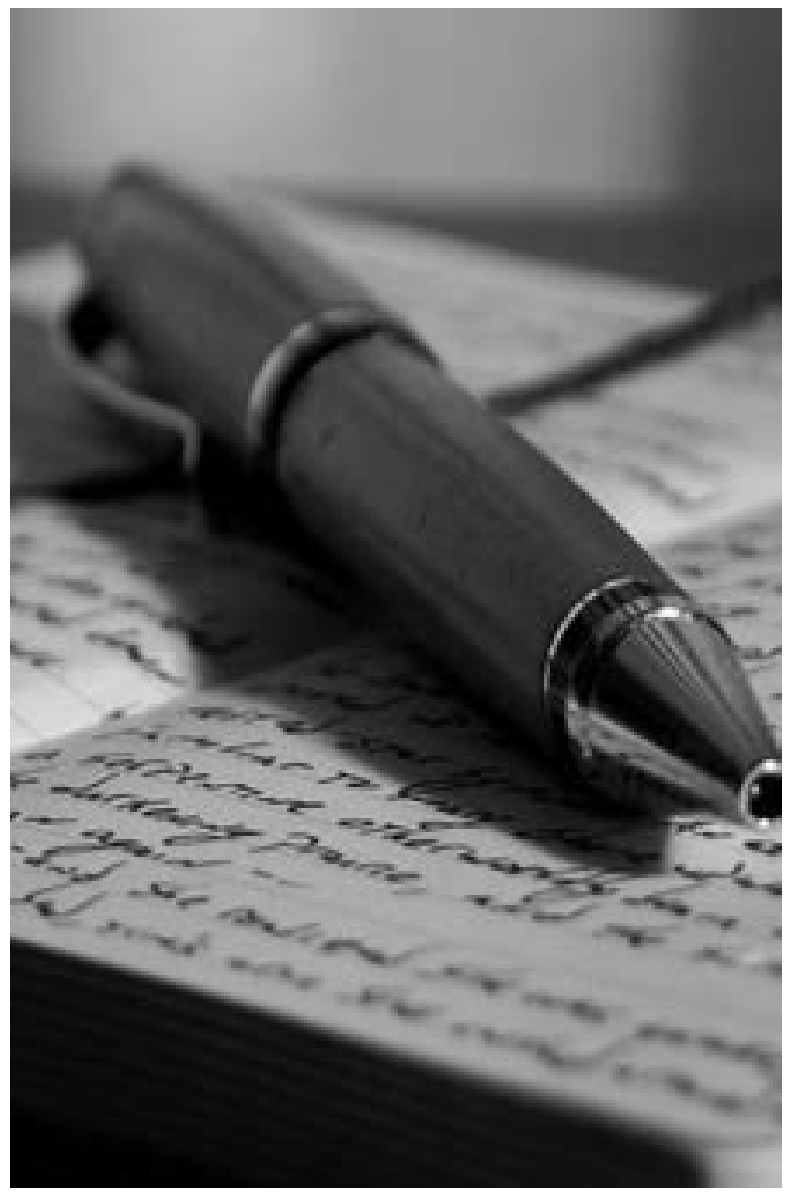




\title{
ANAMNESIS \\ Primer Puesto \\ en el Concurso literario UMCH 2016
}

\author{
Rodrigo M. Freyre Muñoz \\ Estudiante de Administración de la UMCH
}

\begin{abstract}
।
No hay tiempo ni espacio, ni nombres, solo personas y sus almas que se muestran en sus acciones. Él pudo ser artista del Renacimiento, filósofo grecolatino, revolucionario social francés, ermitaño contemplativo en busca de Dios o soldado de las guerras mundiales. Pero ella, ella siempre fue ella.
\end{abstract}

Administraba fotos, luego de largas investigaciones en la red, las otras eran obtenidas a escondidas por él mismo. Coleccionaba recuerdos, coleccionaba su felicidad.

Cuatro frases conformaron su primer cruce de palabras. Ella se marchó con una mochila gigante y él no podía dejar de pensar en aquellos ojos infinitos que acababa de sentir. La vio de espalda alguna vez y sumó un motivo más para seguirla, sus caderas. Libidinoso amor, se dijo.

Un misterio es ella. ¿Qué pensará de mí? ¿Sabrá siquiera mi situación? Miradas cómplices y sensatas fueron muchas veces compartidas entre ellos. De esto se trataba el juego, pero todo juego tiene un ganador y un perdedor. iY en dónde quedan las tablas del ajedrez?

Ella sabe que él la ama, él sabe que ella sabe, pero no cuánto sabe, ni cuánto siente.

Dentro de su estrategia entró la idea de escribirle cartas; sin embargo, antes de realizar aquellas misivas decidió conocer su alma. ¿Cómo hacerlo? Los ojos dicen mucho pero no suficiente. Pasó más de un año de impaciencia enamorada hasta que se enteró, sin casualidad, de que ella escribió un cuento. Añoró la esperanza de que el relato tuviera un mensaje para él.

iNerviosismo adolescente! Descubrió un alma bella, una imaginación rebelde y fantástica, un cariño intenso en busca de ser entregado y bastante de ilusión infantil. iLa niña de la lámpara azul! 
Decidido por la confirmación de sus investigaciones, escribió en un papel sencillo algunas frases sueltas. Sus mejores talismanes.

Su débil engranaje en el pecho, golpeteaba cada vez que la veía. Como un niño ladrón se escondía para verla pasar. El orgullo vencido, se quiere entregar a los brazos de aquella chiquilla tan bonita.

Nunca esperó respuesta alguna. El solo hecho de sentirse leído y saber que por un minúsculo microinstante ella lo ama, es suficiente para sentirse feliz. Le habló de canciones, de poemas, del réquiem de Mozart, de sus impresiones cuando la vio por primera vez y leyó su narración, de la simplicidad de la vida, de ser libres. Eso sí, anónimo.

Nunca se mencionó la palabra amor, aunque es claro que el fundamento del amor se encuentra en la suma de pequeñas partes y el amor solo es una sumatoria final consumada.

La vio bailar y tembló, la vio brillar dorada y se sublimó, la vio sonreír más que nunca y ardió. Quería suponer que no eran casualidades, que todo era para él, pero era demasiado aventurado y poco razonable.

Un viejo que se le apareció por un retirado camino, al verlo tan meditabundo, interrumpió su ensimismamiento para preguntarle la causa. Luego de escucharlo, el anciano invocó a Dionisos y ditirámbicamente entonó una respuesta.

¡Qué extraño y vetusto idioma hablaba! Aun así entendió todo. La anamnesis es la respuesta. Ella siempre fue ella. Ya antes la había escogido, lo que sentía era la chispa de un recuerdo.

Contento por su griego redescubrimiento, se animó a enfrentarla.

La encontró con otro él. Inmediatamente se sintió desbordado y aunque notaba que solo era su perro guardián, padeció al pensar que ella lo ponía de escudo para alejarlo.

- ¿Por qué caminas con él si sabes que tu corto paso es mi aire? Tan gratuita fuiste para regalarme demasiadas sonrisas, y ahora no me dejas pagarte -se dice-. Los vistazos ahora son cuchilladas. 
III

Caminaba y musitaba:

Silencio ensordecedor

caricia áspera

retumba el murmullo

susurra el murmullo

Amatista plástica

barca a la mar

conoces mi secreto

dibujaste mi secreto...

Era imposible culparla por sus depresiones, él ya no quiere errar siguiendo a alguien parecida a mitad de la noche. Irá a la guerra. Se inmolará en sus palabras, en sus labios. Le hablará.

Cuesta tanto armarse de valor para asaltar a una muchacha en flor. Día tras día deambuló, intentando abordar a la ternura hecha mujer, pero para mañana parecía siempre mejor. Mentirosas esperanzas de los cobardes.

Fascinado la observaba en sus movimientos y maneras. Conocía sus rutinas, sus amigas, sus gustos y lugares: es un loco obsesionado. Y es que el amor vuelve locas a las gentes, es autohipnosis, es la expresión máxima de la voluntad, es vivir. Nietzsche, vino hasta mí:

Siempre hay un poco de locura en el amor,

pero siempre hay también un poco de razón en la locura.

IV

Un día se atrevió.

Ella andaba en su carruaje, o a caballo, o quizás era una bicicleta, quién sabe.

-Hola -dijo él-. Dijeron sus labios.

-Te amo -dijo su pupila.

-Hola... -y él no pudo descifrar qué simbolizaba, tal vez nada.

La escena se volvió a repetir, solo un corto cruce de palabras, y un casi adiós de media vuelta, sin verse a la cara. 
“Ella es tímida o no me quiere" -intuyó. Nunca sabremos qué pensó ella.

Repetimos. Ella es un misterio, ella siempre será ella y siempre lo fue.

Él se marchó rápidamente, feliz por habérsele aparecido un momento en su vida y triste por saber que no llevó a nada.

El tiempo sin tiempo pasó, y suponer ilusiones está demás. Pero ella espera intensamente, pese a que no lo parezca, una carta, y él, una respuesta o señal.

Ella es orgullosa y prudente, no cederá. Él fue alumno de un viejo filósofo milesio y solo amará a distancia. No hay medicina para sacarlos de aquel estado anímico. Se extrañan mutuamente ¿Qué es?

\section{$\vee$}

Una noche soñó con ella. La amó. Su cuello de Afrodita fue conquistado a besos, y entre las lunas, hizo verano en su mejilla.

Despertó y las estrellas de la madrugada estaban en su lugar de siempre.

Cogió la vieja y triste guitarra al lado de su cama y llovió una antigua canción de Sui Generis:

Quizás porque no soy de la nobleza

Puedo nombrarte mi reina y princesa

Y darte coronas de papel de cigarrillos

Quizás porque soy un mal negociante

No pido nada a cambio de darte

Lo poco que tengo, mi vida y mis sueños

Quizás porque no soy un buen soldado

Dejo que ataques de frente y costado

Cuando discutimos de nuestros proyectos

Quizás porque no soy nada de eso

Es que hoy estás aquí en mi lecho.

Solo fue una fantasía de su vigilia. Amar y vivir es vigilia. 